\title{
Oil Content and Fatty Acid Composition in Castor (Ricinus communis L.) Genotypes
}

\author{
B.A. Chaudhari ${ }^{1,2^{*}}$, M.P. Patel ${ }^{1,3}$, D.T. Dharajiya ${ }^{4}$, A.M. Patel ${ }^{5}$ and M.R. Thakur ${ }^{2}$
}

${ }^{1}$ Department of Genetics and Plant Breeding, C.P. College of Agriculture, Sardarkrushinagar Dantiwada Agricultural University (SDAU), Sardarkrushinagar, Gujarat, India

${ }^{2}$ Cotton Research Sub-Station, Navsari Agricultural University, Achhalia, Gujarat, India

${ }^{3}$ Pulses Research Station, SDAU, Sardarkrushinagar, Gujarat, India

${ }^{4}$ Bio Science Research Centre, SDAU, Sardarkrushinagar, Gujarat, India

${ }^{5}$ Main Castor-Mustard Research Station, SDAU, Sardarkrushinagar, Gujarat, India

*Corresponding author: drbachaudhary@nau.in (ORCID ID: 0000-0003-4210-8709)

Paper No. 914

Received: 20-06-2021

Revised: 22-08-2021

Accepted: 05-09-2021

\begin{abstract}
Castor (Ricinus communis L.) is an important non-edible oilseed crop with diversified industrial usage. In the present study, twenty-six genotypes of castor were analyzed for total seed oil content using Nuclear Magnetic Resonance (NMR) spectroscopy and fatty acid profiling through gas chromatography with flame-ionization detector (GC-FID) to update the database of this important industrial crop. In the present study, the highest seed oil content was determined in SHB-1019 genotype which was $45.86 \%$. Total saturated fatty acid, steric acid and palmitic acid per cent was recorded higher in SKI-370 genotype which was $3.38 \%, 1.92 \%$ and $1.46 \%$, respectively. Among the all genotypes, the higher per cent of total unsaturated fatty acid, ricinoleic acid and linolenic acid was observed higher in genotype VI-9 whereas, mono unsaturated fatty acid (oleic acid) and poly unsaturated fatty acid (linoleic) was found higher in genotype GEETA. The present study can be very important in the selection of male parents for the development of high ricinoleic acid castor hybrid. This will ultimately help in increasing the production and quality of industrially important oil.
\end{abstract}

\section{HIGHLIGHTS}

(0 Twenty six genotypes of castor were analyzed for total seed oil content through NMR spectroscopy and fatty acid composition through GC-FID.

0 The highest seed oil content (45.86 \%) was determined in SHB-1019 genotype.

( $)$ The highest oleic acid/linoleic acid ratio was 0.536 in SH-72 genotype indicating higher stability of castor oil for industrial applications.

Keywords: Castor, Ricinus communis (L.), Castor oil, Fatty acid composition, GC-FID

Castor (Ricinus communis $\mathrm{L} .2 \mathrm{n}=2 \mathrm{X}=20$ ) resides one of the most important non-edible oilseed crop (Dharajiya et al. 2020). It is hails to mono specific genus Ricinus of Euphorbiaceae family (Chaudhari et al. 2019). It has cross pollination up to the extent of 50 per cent due to its monoecious nature. Castor seed contains 38 to 54 per cent oil (Román-Figueroa et al. 2020; Yadav et al. 2017). The castor oil has extra properties than other vegetable oils, as it does not freeze even under $-12^{\circ} \mathrm{C}$ to $-18^{\circ} \mathrm{C}$ temperature. It is therefore, considered as one of the best lubricating agent particularly for high speed engine and aero planes. Owing to its unique physico-chemical properties, castor oil is used as raw material for

How to cite this article: Chaudhari, B.A., Patel, M.P., Dharajiya, D.T., Patel, A.M. and Thakur, M.R. 2021. Oil Content and Fatty Acid Composition in Castor (Ricinus communis L.) Genotypes. IJAEB, 14(03): 319-324.

Source of Support: None; Conflict of Interest: None (क) 
numerous and varied industrial applications, such as manufactures of polymers, coatings, cosmetics and production of biodiesel (Dharajiya et al. 2020). Due to commercial use and advancement of industrialization, the demand of raw castor oil has been increased all over the world. The refined oil has a good domestic market (Jeong and Park 2009).

Fatty acid of castor oil contains ricinolenic acid, oleic acid, linoleic acid, $\alpha$-linolenic acid, stearic acid, and palmitic acid (Shah et al. 2017). Ricinoleic acid is the major component of castor oil and is normally occupies over 89 per cent of the total fatty acid of the oil (Shah et al. 2017). Fatty acids in castor seeds have been studied since 1970s (Cooper 1971; Lin and Arcinas 2007; Shah et al. 2015). The castor seed are studied much for oil content, but limited attempt has been made for fatty acid profiling of castor oil. Castor industry expects low variability in the fatty acid profile of oil, grown at either different locations or in different years (da Silva Ramos et al. 1984; Ogunniyi 2006; Mutlu and Meier 2010). Therefore, assessing fatty acid profile of as many germplasm as possible is very useful in industrial level to generate database and to set benchmark. By considering these facts, this study was aimed to analyze the total seed oil through Nuclear Magnetic Resonance (NMR) spectroscopy and absolute contents of fatty acids in castor seeds by gas chromatography to update the database of this important industrial crop.

\section{MATERIALS AND METHODS}

Twenty six castor genotypes including eleven hybrids (GAUCH-1, GCH-2, GCH-4, GCH-5, GCH-6, GCH-7, SHB-1005, SHB-1018, SHB-1019, SHB-1029 and GNCH-1), four pistillate lines (VP1, GEETA, JP-65 and SKP-84) and eleven inbred lines (VI-9, JI-35, 48-1, SH-72, JI-96, SKI-215, SKI352, SKI-370, SKI-372, SKI-373 and DCS-94) were grown at Agricultural Research Station, S. D. Agricultural University, Kholwada, Gujarat, India during kharif-rabi 2016-17 with spacing of $120 \mathrm{~cm} \times$ $60 \mathrm{~cm}$. Standard uniform agronomic practices were followed to raise the crop. Biochemical analysis was carried out at Main Castor-Mustard Research Station, SDAU, Sardarkrushinagar, Gujarat, India.

\section{Seed oil content $(\%)$ determination}

Random sample of 45 grams seeds was obtained from the bulk produced from each genotype from each replication the oil content of seeds was obtained by Bench top NMR Analyzer (Oxford instruments, USA).

\section{Fatty acid profiling of seed oil}

Approximately $60 \mathrm{~g}$ dried seeds were collected from each genotype and crushed into uniform texture using mortar-pestle. The crushed seeds were loaded into Soxhlet to extract oil using petroleum ether $\left(60-80^{\circ} \mathrm{C}\right)$ as solvent. The oil was used for fatty acid profiling using gas chromatography with flameionization detector (GC-FID). The oil was converted in to fatty acid methyl ester (FAME) using alkaline catalysed transesterification with $0.5 \mathrm{ml} 4 \% \mathrm{KOH}$ solution in methanol using standard protocol. The instrument (Thermo-Trace GC Ultra-Al 3000 auto sampler) (Thermo Scientific, USA) was programmed as inlet temperature $210^{\circ} \mathrm{C}$ and FID detector temperature was $260^{\circ} \mathrm{C}$. Oven was kept at $160^{\circ} \mathrm{C}$ for two minutes. After that an increase of $10^{\circ} \mathrm{C} / \mathrm{min}$. was applied to raise oven temperature up to $200^{\circ} \mathrm{C}$, where it was kept at isotherm for ten minutes. The gas flow rate in column was $1.5 \mathrm{ml} / \mathrm{min}$. and the sample injection volume was $0.2 \mu \mathrm{l}$. The capillary was TR FAME-30 $\mathrm{m} \times 0.25 \mathrm{~mm}$, ID $\times 0.25 \mu \mathrm{m}$ film. Fatty acids composition of each treatment sample was estimated in percentage by using Chrom-card software associated with GC.

\section{Data analysis}

The data were analysed by Microsoft Excel 2010 to derive different ratios among fatty acids as suggested by Shah et al. (2017). Pearson's correlation coefficients (r) was calculated using PAST 3.22 software (Hammer et al. 2001) to determine significance of correlation among fatty acids at $\mathrm{P}<0.05$.

\section{RESULT AND DISCUSSION}

\section{Seed oil content $(\%)$ determination}

Castor oil has great value in industry, pharmaceutical and agricultural sectors. The variability in seed oil content ranged from 38.25 to $45.86 \%$ with an average of $42.93 \%$. Among the genotypes studied, SHB-1019 (45.86 \%) was significantly higher for oil content imitated by genotypes namely, GCH7 (45.67\%) and GEETA (45.65 \%). The genotype, 
SKI-372 recorded the lowest oil content (38.25\%) (Table 1).

\section{Fatty acid profiling of seed oil}

Total saturated fatty acid content in all castor genotype was ranged from 2.27 to $3.38 \%$ with a mean of $2.70 \%$. It was observed that genotype SKI-370 (3.38\%) had higher per cent of total saturated fatty acid followed by genotypes GEETA $(2.98 \%)$, SKI-372 (2.97\%), and SH-72 (2.96\%). The genotypes VI-9 (2.27\%) had low per cent of total saturated fatty acid. Total saturated fatty acid content was categorized in two type of acids viz., steric acid (C16:0) and palmitic acid (C18:0) (Table $1)$. The amount of steric acid in all castor genotypes was ranged from 1.05 to $1.46 \%$ with a mean of $1.26 \%$. Among all the accessions, SKI-370 (1.46\%) contained highest amount of steric acid, followed by genotypes namely, SHB-1005 (1.14\%), GEETA $(1.14 \%)$, SKI-373 (1.14 \%), and SH-72 (1.40\%). The genotypes, VI-9 (1.05\%) contained lowest amount of steric acid. Palmitic acid content in all castor

Table 1: Seed oil content and fatty acid profile of castor genotypes

\begin{tabular}{|c|c|c|c|c|c|c|c|c|c|}
\hline \multirow{4}{*}{ Genotype } & \multirow{4}{*}{$\begin{array}{l}\text { Oil content } \\
(\%)\end{array}$} & \multicolumn{8}{|c|}{ Fatty acid composition (\%) } \\
\hline & & \multirow{2}{*}{\multicolumn{3}{|c|}{ SFA }} & \multicolumn{5}{|c|}{ UFA } \\
\hline & & & & & \multirow{2}{*}{$\begin{array}{l}\text { MUFA } \\
\text { C18:1 } \\
\end{array}$} & \multirow{2}{*}{$\begin{array}{l}\text { PUFA } \\
\text { C18:2 }\end{array}$} & \multicolumn{2}{|r|}{ RA } & \multirow{2}{*}{ Total } \\
\hline & & C16:0 & C18:0 & Total & & & C18:3 & $\mathrm{C} 18: 1(\mathrm{OH})$ & \\
\hline GAUCH-1 & 43.13 & 1.18 & 1.36 & 2.54 & 3.26 & 4.71 & 0.5 & 88.98 & 97.45 \\
\hline GCH-2 & 44.93 & 1.24 & 1.52 & 2.76 & 3.95 & 5.1 & 0.57 & 87.62 & 97.24 \\
\hline GCH-4 & 43.67 & 1.20 & 1.35 & 2.55 & 3.1 & 4.91 & 0.61 & 88.83 & 97.45 \\
\hline GCH-5 & 43.03 & 1.28 & 1.4 & 2.68 & 3.28 & 4.95 & 0.53 & 88.55 & 97.31 \\
\hline GCH-6 & 44.09 & 1.28 & 1.38 & 2.66 & 3.01 & 4.78 & 0.59 & 88.96 & 97.34 \\
\hline GCH-7 & 45.67 & 1.15 & 1.24 & 2.39 & 2.67 & 4.71 & 0.61 & 89.62 & 97.61 \\
\hline SHB-1005 & 44.21 & 1.41 & 1.49 & 2.9 & 3.87 & 5.34 & 0.64 & 87.25 & 97.1 \\
\hline SHB-1018 & 42.54 & 1.20 & 1.25 & 2.45 & 2.65 & 4.85 & 0.57 & 89.48 & 97.55 \\
\hline SHB-1019 & 45.86 & 1.20 & 1.43 & 2.63 & 3.81 & 5.04 & 0.57 & 87.96 & 97.38 \\
\hline SHB-1029 & 44.52 & 1.23 & 1.41 & 2.64 & 3.36 & 4.88 & 0.62 & 88.5 & 97.36 \\
\hline GNCH-1 & 42.46 & 1.16 & 1.35 & 2.51 & 3.31 & 4.75 & 0.56 & 88.87 & 97.49 \\
\hline VP-1 & 40.04 & 1.27 & 1.46 & 2.73 & 3.00 & 5.15 & 0.65 & 88.48 & 97.28 \\
\hline GEETA & 45.65 & 1.41 & 1.57 & 2.98 & 4.26 & 5.82 & 0.55 & 86.39 & 97.02 \\
\hline JP-65 & 40.50 & 1.26 & 1.49 & 2.75 & 3.44 & 4.89 & 0.61 & 88.33 & 97.27 \\
\hline SKP-84 & 40.20 & 1.11 & 1.35 & 2.46 & 3.47 & 4.74 & 0.55 & 88.8 & 97.56 \\
\hline VI-9 & 44.50 & 1.05 & 1.22 & 2.27 & 2.1 & 3.87 & 0.89 & 91.29 & 98.15 \\
\hline JI-35 & 43.73 & 1.22 & 1.68 & 2.9 & 4.06 & 4.98 & 0.52 & 87.56 & 97.12 \\
\hline 48-1 & 42.00 & 1.26 & 1.61 & 2.87 & 3.43 & 5.25 & 0.56 & 87.9 & 97.14 \\
\hline SH-72 & 41.23 & 1.40 & 1.56 & 2.96 & 2.76 & 5.15 & 0.65 & 88.49 & 97.05 \\
\hline JI-96 & 43.99 & 1.37 & 1.56 & 2.93 & 3.73 & 4.75 & 0.52 & 88.07 & 97.07 \\
\hline SKI-215 & 45.50 & 1.30 & 1.45 & 2.75 & 2.92 & 5.38 & 0.6 & 88.35 & 97.25 \\
\hline SKI-352 & 42.20 & 1.35 & 1.6 & 2.95 & 3.87 & 4.82 & 0.52 & 87.85 & 97.06 \\
\hline SKI-370 & 41.17 & 1.46 & 1.92 & 3.38 & 3.97 & 5.66 & 0.64 & 86.37 & 96.64 \\
\hline SKI-372 & 38.25 & 1.14 & 1.3 & 2.44 & 2.97 & 4.69 & 0.59 & 89.32 & 97.57 \\
\hline SKI-373 & 41.50 & 1.41 & 1.56 & 2.97 & 3.18 & 5.41 & 0.62 & 87.83 & 97.04 \\
\hline DCS-94 & 41.51 & 1.13 & 1.42 & 2.55 & 3.07 & 4.46 & 0.46 & 89.47 & 97.46 \\
\hline Mean & 42.93 & 1.26 & 1.46 & 2.70 & 3.33 & 4.96 & 0.59 & 88.41 & 97.30 \\
\hline Maximum & 45.86 & 1.46 & 1.92 & 3.38 & 4.26 & 5.82 & 0.89 & 91.29 & 98.15 \\
\hline Minimum & 38.25 & 1.05 & 1.22 & 2.27 & 2.10 & 3.87 & 0.46 & 86.37 & 96.64 \\
\hline
\end{tabular}

C16:0: Steric acid; C18:0: Palmitic acid; C18:1: Oleic acid; C18:1(OH): Ricinoleic acid; C18:2: Linoleic acid; C18:3: Linolenic acid; MUFA: Mono Unsaturated Fatty Acid; PUFA: Poly Unsaturated Fatty Acid; RA: Ricinoleic acid; SFA: Saturated Fatty Acid; UFA: Unsaturated Fatty Acid. 
genotypes was ranged from $1.22 \%$ (VI-9) to $1.92 \%$ (SKI-370) with a mean (1.46\%). From the perusal of data genotype SKI-370 (1.92\%) found the highest amount of palmitic acid, followed by genotypes viz., JI-35 (1.68 \%) and 48-1 (1.61 \%).

Total unsaturated fatty acid content in all castor genotypes was ranged from $96.64 \%$ (SKI-370) to $98.15 \%$ (VI-9) with a mean $97.30 \%$ (Table 1). Mono unsaturated fatty acid (MUFA) oleic acid (C18:1) content in all castor genotype was ranged from 2.10 $\%$ (VI-9) to $4.26 \%$ (GEETA) with a mean of $3.33 \%$. It was observed that genotype GEETA (4.26\%) had higher per cent of oleic acid followed by genotypes i.e. JI-35 (4.06 \%) and SKI-370 (3.97\%) (Table 1). Poly unsaturated fatty acid (PUFA) in castor oil contained linoleic acid (C18:2) and linolenic acid (C18:3) (Table 1). Linoleic acid content ranged from 3.87 to $5.82 \%$ with a mean of $4.96 \%$. Among the all genotypes the highest per cent of linoleic acid was recorded in $5.82 \%$ for genotype GEETA followed by genotypes, SKI-370 (5.66 \%) and SKI-373 (5.41 \%). The lowest per cent of linoleic acid was recorded in genotype VI-9 (3.87 \%). The values for linolenic acid in castor genotypes ranged from 0.46 (DCS-94) to $0.89 \%$ (VI9) with a mean of $0.59 \%$ (Table 1 ).

Ricinoleic acid, the predominant mono unsaturated fatty acid varied among castor genotypes from 86.37 to $91.29 \%$ with a mean. Among all the genotypes the higher per cent of ricinolenic acid was recorded in genotype viz., VI-9 (91.29 \%) followed by genotype namely, GCH-7 (89.62\%) and SHB$1018(89.48 \%)$. The lowest per cent of ricinolenic acid was recorded in genotypes SKI-370 (86.37\%) (Table 1). The results of the present study are in agreement with the results reported by Huang et al. (2015), Shah et al. (2015), Omari et al. (2015), Omohu and Omale (2017) and Shah et al. (2017). Linolenic acid and oleic acid in castor oil are very much favorable to human health and have been used in the treatments of some human diseases like skin cancer, diabetes, heart attack, high blood pressure, high cholesterol level, renal disease, and lupus (Ganesan et al. 2018). Linoleic acid, palmitic acid, and stearic acid contain certain beneficial properties for the skin, hence utilized in cosmetic industries (Ganesan et al. 2018). Esters of stearic acid: glycol stearate, glycol distearate, and ethylene glycol have been utilized in manufacturing various cosmetic products and in shampoos to increase the pearly effect. The presence of such fatty acids in castor oil offers the industrial and nutritional benefits of castor (Yeboah et al. 2020). The amount of different fatty acids present in castor oil is represented in Fig. 1 . Based on the amount of different beneficial fatty acids in the oil, genotypes can be utilized in further breeding programs.

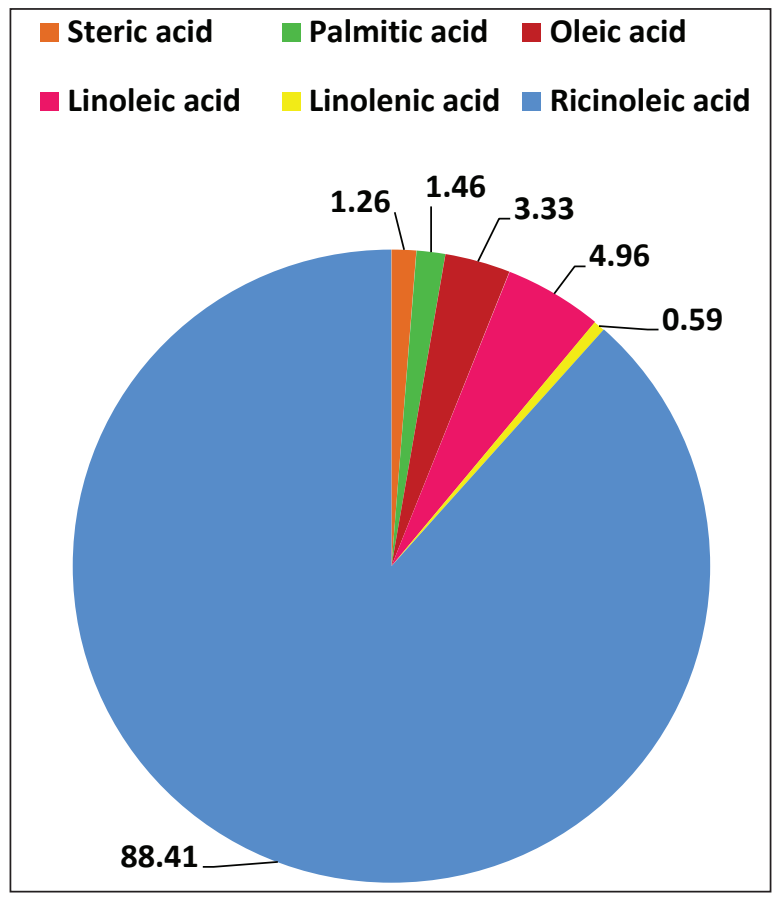

Fig. 1: Contribution of different fatty acids in castor seed oil (Based on data collected from 26 genotypes)

Significant positive correlation was observed between palmitic acid and stearic acid $\left(r=0.750^{*}\right)$. The oleic acid showed significantly positive correlation with palmitic acid $\left(\mathrm{r}=0.691^{*}\right)$ and stearic acid $\left(\mathrm{r}=0.498^{*}\right)$ (Table 2$)$. These results were resembled with the findings of Shah et al., (2017). The linoleic acid has significantly positive correlation with oleic acid $\left(\mathrm{r}=0.582^{*}\right)$, palmitic acid $\left(\mathrm{r}=0.670^{*}\right)$ and stearic acid $\left(\mathrm{r}=0.794^{*}\right)$. However, the linolenic acid has negative correlation with stearic acid $(r=0.088)$, palmitic acid $(r=-0.193)$, oleic acid ( $r$ $\left.=-0.509^{*}\right)$ and linoleic acid $(r=-0.211)$. In the present study, the ricinoleic acid content was significantly negatively correlated with stearic acid $\left(\mathrm{r}=-0.793^{*}\right)$, palmitic acid $\left(\mathrm{r}=-0.836^{*}\right)$, oleic acid $\left(\mathrm{r}=-0.876^{*}\right)$ and linoleic acid $\left(r=-0.884^{*}\right)$ and positive and nonsignificant correlation with linolenic acid $\left(r=0.360^{*}\right)$ (Fig. 2). These results were in agreement with the findings of Shah et al. (2017). 


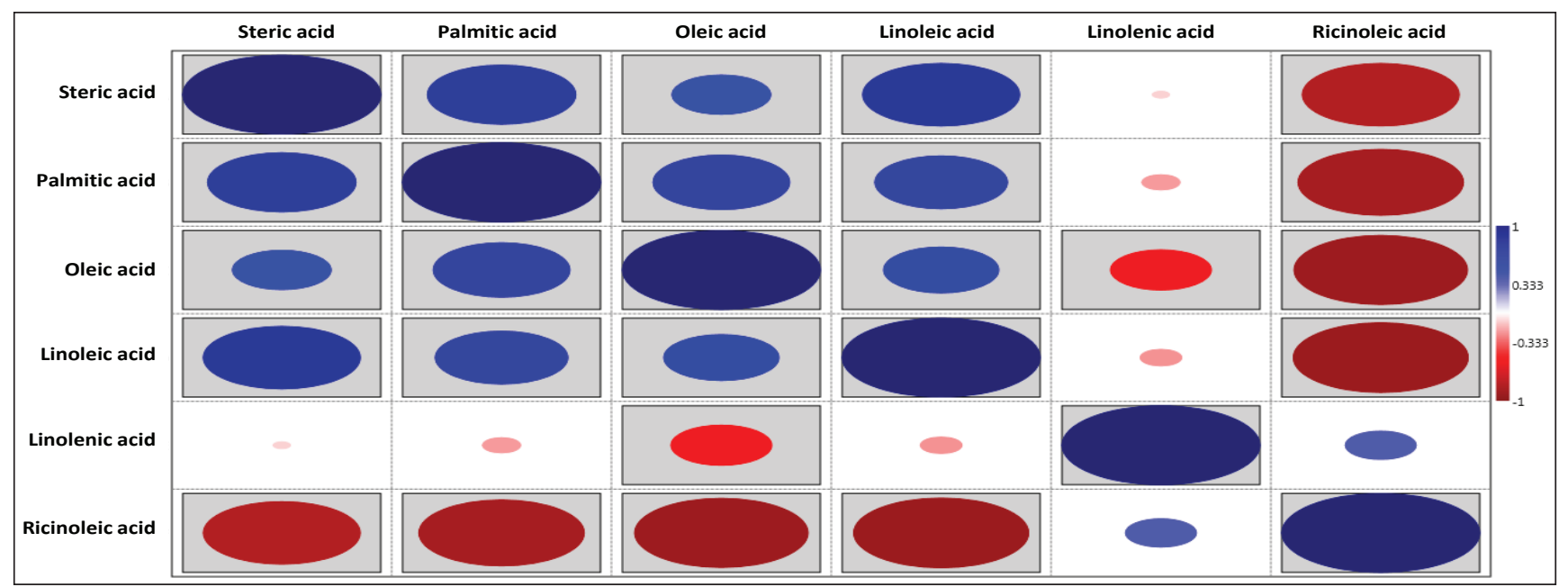

Fig. 2: Correlation analysis among different fatty acids in castor oil (Grey boxes represent significance at $\mathrm{P}<0.05$ )

Table 2: Correlation coefficients among different fatty acids in castor oil

\begin{tabular}{|c|c|c|c|c|c|}
\hline & $\begin{array}{l}\text { Steric } \\
\text { acid }\end{array}$ & $\begin{array}{l}\text { Palmitic } \\
\text { acid }\end{array}$ & $\begin{array}{l}\text { Oleic } \\
\text { acid }\end{array}$ & $\begin{array}{l}\text { Linoleic } \\
\text { acid }\end{array}$ & $\begin{array}{l}\text { Linolenic } \\
\text { acid }\end{array}$ \\
\hline $\begin{array}{l}\text { Palmitic } \\
\text { acid }\end{array}$ & $0.750^{*}$ & & & & \\
\hline Oleic acid & $0.498^{*}$ & $0.691^{*}$ & & & \\
\hline $\begin{array}{l}\text { Linoleic } \\
\text { acid }\end{array}$ & $0.794^{*}$ & $0.670^{*}$ & $0.582^{*}$ & & \\
\hline $\begin{array}{l}\text { Linolenic } \\
\text { acid }\end{array}$ & -0.088 & -0.193 & $-0.509^{*}$ & -0.211 & \\
\hline $\begin{array}{l}\text { Ricinoleic } \\
\text { acid }\end{array}$ & $-0.793^{*}$ & $-0.836^{*}$ & $-0.876^{*}$ & $-0.884^{*}$ & 0.360 \\
\hline
\end{tabular}

* Represents significance at $P<0.05$.

Different ratios among fatty acids of castor genotypes are shown in Table 3. The Oleic acid/ricinoleic acid ratio among the all the genotypes ranged from 0.023 (VI-9) to 0.049 (GEETA). High oleic acid and low ricinoleic acid content in castor oil is preferable for industrial applications demanding high oxidative stability like bio-fuel requiring lower ricinoleic acid content than the standard castor oil (RojasBarros et al. 2004). The oleic acid/linoleic acid (O/L) ratio among all the genotypes ranged from 0.536 (SH-72) to 0.815 (JI-35). Higher O/L ratio showed higher stability of castor oil (Shah et al. 2015). For the improvement of character through selection, it is necessary to understand the extent of diversity existing for each character in germplasm (Parita et al. 2018). This will enhance the development of new varieties using plant breeding (Gelotar et al. 2019). The estimation of seed oil content and fatty acid profiling can be utilized for selection of parents for population development and improvement in oil quantity as well as quality.

Table 3: Different ratios among fatty acids of castor genotypes

\begin{tabular}{|c|c|c|c|}
\hline Genotypes & $\begin{array}{l}\text { Oleic acid/ } \\
\text { Linoleic acid } \\
(\mathrm{O} / \mathrm{L})\end{array}$ & $\begin{array}{l}\text { MUFA/ } \\
\text { PUFA }\end{array}$ & $\begin{array}{l}\text { Oleic acid/ } \\
\text { Ricinoleic acid } \\
\text { (MUFA/RA) }\end{array}$ \\
\hline GAUCH-1 & 0.693 & 0.626 & 0.037 \\
\hline GCH-2 & 0.774 & 0.696 & 0.045 \\
\hline GCH-4 & 0.630 & 0.561 & 0.035 \\
\hline GCH-5 & 0.663 & 0.599 & 0.037 \\
\hline GCH-6 & 0.629 & 0.560 & 0.034 \\
\hline GCH-7 & 0.565 & 0.500 & 0.030 \\
\hline SHB-1005 & 0.724 & 0.646 & 0.044 \\
\hline SHB-1018 & 0.547 & 0.490 & 0.030 \\
\hline SHB-1019 & 0.755 & 0.678 & 0.043 \\
\hline SHB-1029 & 0.689 & 0.611 & 0.038 \\
\hline GNCH-1 & 0.696 & 0.622 & 0.037 \\
\hline VP-1 & 0.582 & 0.517 & 0.034 \\
\hline GEETA & 0.732 & 0.669 & 0.049 \\
\hline JP-65 & 0.704 & 0.626 & 0.039 \\
\hline SKP-84 & 0.732 & 0.656 & 0.039 \\
\hline VI-9 & 0.543 & 0.441 & 0.023 \\
\hline JI-35 & 0.815 & 0.738 & 0.046 \\
\hline $48-1$ & 0.653 & 0.590 & 0.039 \\
\hline SH-72 & 0.536 & 0.476 & 0.031 \\
\hline JI-96 & 0.786 & 0.708 & 0.042 \\
\hline SKI-215 & 0.543 & 0.488 & 0.033 \\
\hline SKI-352 & 0.803 & 0.724 & 0.044 \\
\hline SKI-370 & 0.701 & 0.630 & 0.046 \\
\hline
\end{tabular}




\begin{tabular}{llll} 
SKI-372 & 0.633 & 0.562 & 0.033 \\
SKI-373 & 0.588 & 0.527 & 0.036 \\
DCS-94 & 0.689 & 0.625 & 0.034 \\
Mean & 0.669 & 0.599 & 0.038 \\
Max & 0.815 & 0.738 & 0.049 \\
Min & 0.536 & 0.441 & 0.023 \\
\hline
\end{tabular}

\section{CONCLUSION}

On the basis of the results obtained, it was concluded that among the genotypes evaluated, the maximum oil content was $45.86 \%$ in seeds of SHB-1019. The maximum amount of ricinoleic acid $(91.29 \%)$ was recorded in VI-9. The present study can be very important in the selection of male parents for the development of high ricinoleic acid castor hybrid.

\section{ACKNOWLEDGEMENTS}

The authors grateful to the authorities of at Main Castor-Mustard Research Station, Sardarkrushinagar and Agricultural Research Station, Kholwada, SDAU, Gujarat, India for providing requirements to conduct the research work.

\section{REFERENCES}

Chaudhari, B.A., Patel, M.P., Dharajiya, D.T. and Tiwari, K.K. 2019. Assessment of genetic diversity in castor (Ricinus communis L.) using microsatellite markers. BioSci. Biotech. Res. Asia, 16(1): 61-69.

Cooper, T.G. 1971. The activation of fatty acids in castor bean endosperm. J. Biol. Chem., 246(11): 3451-3455.

da Silva Ramos, L.C., Tango, J.S., Savi, A. and Leal, N.R. 1984. Variability for oil and fatty acid composition in castorbean varieties. J. Am. Oil Chemists' Soc., 61(12): 1841-1843.

Dharajiya, D.T., Shah, A., Galvadiya, B.P., Patel, M.P., Srivastava, R., Pagi, N.K., Solanki, S.D., Parida, S.K. and Tiwari, K.K. 2020. Genome-wide microsatellite markers in castor (Ricinus communis L.): Identification, development, characterization, and transferability in Euphorbiaceae. Indus. Crops and Prod., 151: 112461.

Ganesan, K., Sukalingam, K. and Xu, B. 2018. Impact of consumption and cooking manners of vegetable oils on cardiovascular diseases-A critical review. Trends in Food Sci. and Tech., 71: 132-154.

Gelotar, M.J., Dharajiya, D.T., Solanki, S.D., Prajapati, N.N., and Tiwari, K.K. 2019. Genetic diversity analysis and molecular characterization of grain amaranth genotypes using inter simple sequence repeat (ISSR) markers. Bulletin of the National Res. Centre, 43(1): 1-10.

Hammer, Ø., Harper, D.A. and Ryan, P.D. 2001. PAST: Paleontological statistics software package for education and data analysis. Palaeontologia Electronica, 4(1): 9.
Huang, F., Peng, C.B.M., Zhu, G., He, Z., Chen, X., Luo, R., and Zhao, Y. 2015. Chromatographic analysis of fatty acid composition in differently sized seeds of castor accessions. Biotech. and Biotechnological Equip., 29(5): 892-900.

Jeong, G.T. and Park, D.H. 2009. Optimization of biodiesel production from castor oil using response surface methodology. Appl. Biochem. and Biotech., 156(1): 1-11.

Lin, J.T. and Arcinas, A. 2007. Regiospecific analysis of diricinoleoylacylglycerols in castor (Ricinus communis L.) oil by electrospray ionization- mass spectrometry. J. Agric. and Food Chem., 55(6): 2209-2216.

Mutlu, H. and Meier, M.A. 2010. Castor oil as a renewable resource for the chemical industry. European J. Lipid Sci. and Tech., 112(1): 10-30.

Ogunniyi, D.S. 2006. Castor oil: a vital industrial raw material. Bioresource Tech., 97(9): 1086-1091.

Omari, A., Mgani, Q.A. and Mubofu, E.B. 2015. Fatty acid profile and physico-chemical parameters of castor oils in Tanzania. Green and Sustainable Chem., 5: 154-163.

Omohu, O.J. and Omale, A.C. 2017. Physicochemical properties and fatty acid composition of castor bean (Ricinus communis L.) seed oil. European J. Biophy., 5(4): 62-65.

Parita, B., Kumar, S.N., Darshan, D. and Karen, P. 2018. Elucidation of genetic diversity among ashwagandha [Withania somnifera (L.) Dunal] genotypes using EST-SSR markers. Res. J. Biotech., 13(10): 52-59.

Rojas-Barros, P., de Haro, A., Munoz, J. and FernándezMartínez, J.M. 2004. Isolation of a natural mutant in castor with high oleic/low ricinoleic acid content in the oil. Crop Sci., 44(1): 76-80.

Román-Figueroa, C., Cea, M., Paneque, M. and González, M.E. 2020. Oil content and fatty acid composition in castor bean naturalized accessions under Mediterranean conditions in Chile. Agronomy, 10(8): 1145.

Shah, S.K., Joshi, A.V., Patel, A.M. and Patel, D.K. 2017. Screening of castor genotypes for ricinoleic acid content. Int. J. Cur. Microb. and Appl. Sci., 6(8): 1318-1324.

Shah, S.K., Patel, D.K., Patel, R.M. and Patel, P.S. 2015. Seed and oil quality characteristics of some castor (Ricinus communis L.) inbred lines. Int. J. Agric., Env. and Biotech., 8(1): 177-181.

Yadav, P. and Anjani, K. 2017. Assessment of variation in castor genetic resources for oil characteristics. J. Am. Oil Chemists' Soc., 94(4): 611-617.

Yeboah, A., Ying, S., Lu, J., Xie, Y., Amoanimaa-Dede, H., Boateng, K.G.A., Chen, M. and Yin, X. 2020. Castor oil (Ricinus communis): a review on the chemical composition and physicochemical properties. Food Sci. and Tech., https://doi.org/10.1590/fst.19620. 